\title{
Prediction of carcass fat from body measurements made on live rats differing in age, sex and strain
}

\author{
By MARY W. MARSHALL, BARBARA P. SMITH, ARVID W. MUNSON* \\ AND RICHARD P. LEHMANN† \\ Human Nutrition Research Division and Biometrical Services, \\ Agricultural Research Service, United States Department of Agriculture, \\ Beltsville, Maryland
}

(Received 7 October I968-Accepted 30 December 1968)

I. Individual body fat and body measurements such as lengths, girths and selected skinfold thicknesses were determined in our laboratory strain (BHE), a highly inbred strain (IN) of BHE rats and in a strain of Wistar rats. Measurements were made on unconscious rats in less than 5 min per rat just before autopsy; body fat content was determined in individual rats of both sexes at 50,100 and 300 days of age.

2. Among the strains, mean total body fat was highest in BHE rats at each age; IN rats of similar average body size were leanest. Statistically significant differences in body fat among the strains were due primarily to differences among the male rats at 300 days. Total protein and skeletal mass increased with increases in age and body size, as did body fat in rats after maturity. IN rats had the largest fat-free weights. Although significant age differences in body fat and body measurements occurred, they were in part dependent upon changes in bodyweight, sex and strain of the animals. Female rats had more fat per unit body-weight than males at each age studied. Females, though fatter than males, had smaller skinfold thicknesses, indicating that female fat increases are primarily in visceral fat.

3. Large variation in fat among individuals within strains of the same body-weight and age suggests a genetic influence in fat potential in rats not associated with age or body-weight.

4. Results from multiple regression analyses showed differences among adjusted means and partial regression coefficients due to strain and sex of the animals. Although final body-weight was the predictor common to all equations, body length, abdominal girth and subscapular skinfold were common to all but one set of equations. Chest girth, tibia length, triceps and abdominal skinfolds decreased in frequency of appearance in that order. Some of the measurements were more effective predictors at one age than at another. It was clearly necessary to take into account body dimensions other than weight to obtain an optimal prediction of body fat.

5. Differences in characteristics of the rats support the concept of genetic influences in fat deposition in individuals and indicate the complex nature of these influences.

Several reports from this laboratory have dealt primarily with three strains of rats: (I) a strain (BHE) developed in the laboratory by crossing albino (Yale strain origin) and black and white hooded rats (Pennsylvania State College origin); (2) a highly inbred strain (IN), a line with larger but leaner bodies than the BHE parent strain; and (3) Wistar rats. The three strains have shown important differences in their nutritional responses, some of which are reflected in differences in liver and body fat content (Marshall \& Hildebrand, 1963; Adams, 1964; Durand, Fisher \& Adams, I964; Lakshmanan \& Adams, 1965; Taylor, Conway, Schuster \& Adams, 1967; M. W. Marshall, B. P. Smith \& R. P. Lehmann, unpublished results). Differences in food intake have not accounted for the strain differences (Marshall \& Hildebrand, I963). It seemed possible that the different strains provided a basis for

* Present address: Ralston Purina Company, Checkerboard Square, Saint Louis, Missouri.

+ Present address: Bureau of Veterinary Medicine, Food and Drug Administration, Arlington, Virginia. 
selective breeding studies to yield rats with different potential for obesity. To study metabolic differences associated with genetic variations in fat content of individuals, there is a need to find ways of evaluating, with the use of simple and rapid techniques, the fat content of many individual live animals to establish a basis for selection. Thus body measurements such as weights, lengths, girths and selected skinfold thicknesses were made on rats of the three strains at three ages, maintained under the same conditions and fed on the same commercial stock diet.

This paper deals with a comparison of the measurements and composition of the rats as influenced by strain, age and sex, and the correlation of the individual measurements with body fat as a measure of their usefulness as predictors of individual fat contents of the live animal. In addition, an evaluation of the body measurements as multiple indicators is presented, including regression equations, for the best estimation of fat content.

\section{EXPERIMENTAL}

\section{Rats and their management}

The origin of both BHE and Wistar rats has been previously described (Marshall \& Hildebrand, I963). BHE rats were maintained by a random type closed-colony breeding system for the past ten generations. The inbred (IN) rats were maintained by full-sib matings for eleven generations, selected for large size in the eleventh generation, and full-sib matings continued. Rats of the Wistar strain were kept in the same quarters as the BHE rats for ten generations under an identical breeding system during a similar period.

All of the animals were weaned at 2 I-25 days of age depending upon when the individual rats of the litters (litters in excess of ten rats were reduced at random at birth to ten each) reached a minimum of $40 \mathrm{~g}$. First, second or third litters were used. They were distributed proportionately among eighteen groups (two sexes $x$ three ages $\times$ three strains). The animals were housed in wire mesh cages under similar conditions, three to five rats per cage at weaning; when they reached roo days of age males were reduced to three rats for each cage. Animal quarters were air-conditioned throughout the year at $75-80^{\circ} \mathrm{F}$ and $40-50 \%$ relative humidity. Lighting was regulated to give $\mathrm{I} 2 \mathrm{~h}$ of uniform illumination and $\mathrm{I} 2 \mathrm{~h}$ of darkness each day.

Altogether, 7 ro rats in the eighteen groups were evaluated-both sexes of three strains at $50 \pm 2,100 \pm 2$ or $300 \pm 8$ days. (Since average ages were almost identical, no age corrections were made). All rats were fed on the same pelleted stock diet (Purina Laboratory Chow; Ralston Purina Company) and had access to distilled water ad lib. All animals were weighed weekly. They were not fasted before necropsy.

\section{Body measurements}

All measurements reported were done on anaesthetized rats. Several hundred rats were measured before evaluations were begun to establish that the measurements could be reproduced. Nearly all measurements were made by one individual. Upon reaching the desired age, apparently healthy rats were selected, weighed, anaesthetized with sodium amytal solution and measured as soon as they lost consciousness. 
Total body length. The animal was placed, abdomen down, on a sheet of graph paper marked in $\mathrm{cm}$. The nose was placed at the top of the sheet and total body length measured from its tip as it touched the top line (as viewed by the measurer from above) to the anus. The nape of the neck was stretched forward as the tail was pulled backward. This simple procedure (Acheson, Macintyre \& Oldham, 1959) was quite satisfactory for 50 -day-old conscious and all unconscious rats.

Tibia length. The length of the right, lower leg was measured from the patella to the lateral malleolus; it is referred to herein as the tibia length.

Tail length. The animal was placed at the top of the graph paper and the tail stretched from the anus to its tip.

Girths. A cloth Lufkin tape marked in $\mathrm{cm}$ was used. The rat was held upright by the nape of the neck and, while in this position, the tape was stretched, (I) around the chest at the xyphoid level and (2) around the abdomen approximately $2.5 \mathrm{~cm}$ below the umbilical level.

Skinfold thicknesses. While the rat was still in the upright position skinfold measurements were made with a calibrated Lange caliper. Readings were taken while holding the caliper horizontal to the upright posture of the rat. The three skinfolds selected were those which had provided information on fatness in man (Hammond, 1955; Tanner, 1959): (I) below the tip of the right scapula, (2) right triceps, and (3) I in. below the umbilical level. When it became apparent that neither triceps nor abdominal skinfolds were providing large variations in thickness, the right leg skinfold thickness (groin area) was added. Skinfold measurements were presumed to be representative of the species.

\section{Carcass analysis}

As soon as the measurements were completed the body cavity was opened and $3 \mathrm{ml}$ blood were removed by heart puncture from 100- and 300-day-old animals. (No blood was removed from 50-day-old rats.) Any evidence of gross abnormalities was recorded. The stomach and entire gastro-intestinal tract were removed and emptied of their contents. The carcasses, including the organs after weighing, were placed in individually tared jars, sealed, reweighed and autoclaved at $120^{\circ}$ for $\mathrm{I} 5 \mathrm{~min}$, to facilitate homogenizing of skin and tail, and then frozen until analysed for fat. Organ weights and serum cholesterol of the rats in this study will be reported later.

The entire carcass was homogenized in a heavy duty blender after partial thawing with twice its weight of distilled water. This required a maximum of $5 \mathrm{~min}$. Fat was determined gravimetrically after acid hydrolysis and extraction with ethyl ether and light petroleum in modified Mojonnier tubes. Pooled samples of rats of each age, strain and sex group were prepared by combining either 5 or $10 \%$ of the total homogenate and re-homogenizing; they were analysed for moisture, ash, protein and fat.

\section{Statistical procedures}

Results were analysed by the method of least squares (Harvey, 1960). A model was fitted which measured the effects due to age, sex and strain. In addition, the effects of which particular age-sex, age-strain and sex-strain subclass a rat came from were fitted in the model. That is to say, there is an effect of a rat being a male and an effect 
of being an IN rat and in addition there is an effect of being both a male and an IN rat. This we shall call the interaction of sex and strain. A further analysis was then undertaken to consider the effect of final body-weight on the variables measured. The effect of final body-weight was removed statistically from the sex, strain and age effects to determine whether the sex, strain and age differences were real or due to differences in final body-weight.

The $t$ test was used to evaluate differences among the various subclass means after the analysis of variance. Simple correlation coefficients were calculated for $g$ body fat $(Y)$ v. the variables $(X)$ for individual rats in each age, sex and strain group.

For the formulation of multiple regression equations a model was fitted which permitted the elimination of body measurements that did not significantly contribute to the prediction of total carcass fat. The model used contained 5 degrees of freedom for the sex-strain subclass groups as well as the continuous variables and the interaction of sex and strain separately with the continuous independent variables. This approach further allows the fitting of the three-way interaction of the continuous variables by sex-strain subclasses; the model contained I degree of freedom for the average regression. When there was a difference in the relationship between the $X$ and $Y$ variables in the various sex-strain subclasses, this difference was considered, otherwise the average regression was used. The variance in each model represented not only the variation due to the body measurements ( $X$ variables) but to sex and strain of the rats as well. Results for rats of both sexes of each of the three age groups were treated separately. Thus, for each age group predictions cannot be made for animals outside the ranges of values included in the analysis.

\section{RESULTS}

\section{General considerations}

Raw means for body-weight; body composition, lengths of body, tibia and tail; chest and abdominal girths and four skinfold thicknesses are presented in Tables $\mathrm{I}$ and 2 for animals grouped by age, strain and sex. Table 3 gives the results for body fat and body measurements adjusted for body-weight. The presence of statistically significant interaction between two main effects such as age and sex requires a different interpretation from the usual. In some instances, differences between means, which were statistically significant because of the large numbers of rats involved in the error mean square, were too small to be of biological importance. However, several points were clearly demonstrated. One of the points that will be emphasized is that though body-weight is strongly associated with age, sex and strain it does not fully explain age, sex or strain differences in many of the variables measured.

Effect of age. Results of the analysis of variance showed that, as expected, bodyweight, total body fat and all body measurements increased significantly with age. But, since nearly all age-strain and age-sex interaction terms were significant, these differential effects will be discussed further. Adjusting the results to account for differences in body-weight of the animals removed the significance only for differences in abdominal girth and the triceps skinfold thickness. 
Vol. 23

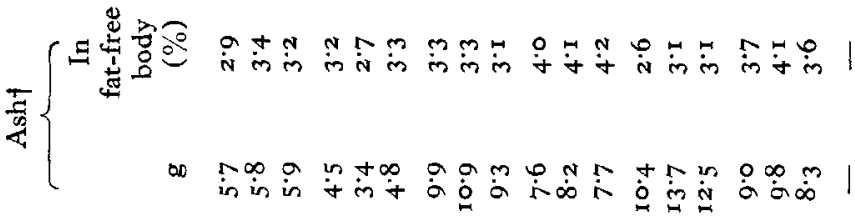

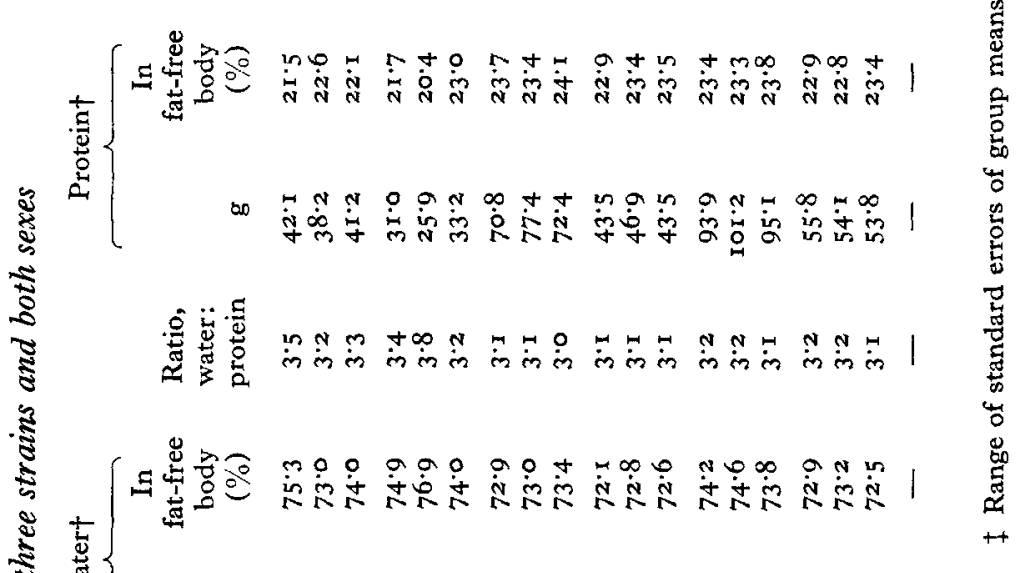

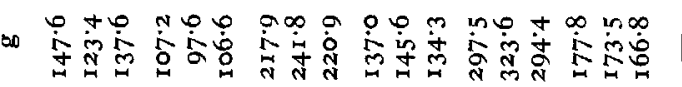

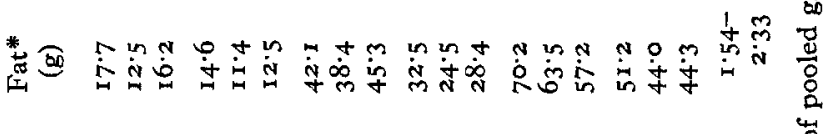

है

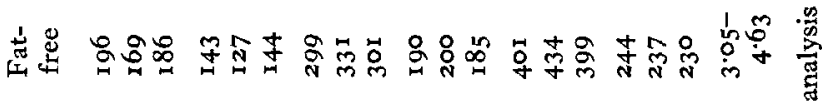

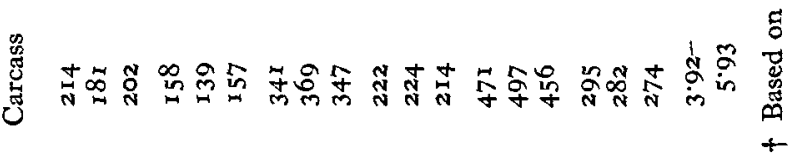

ॐ0

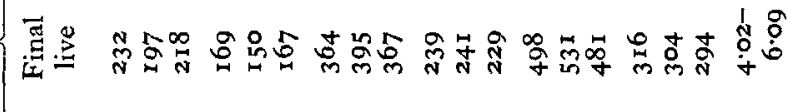

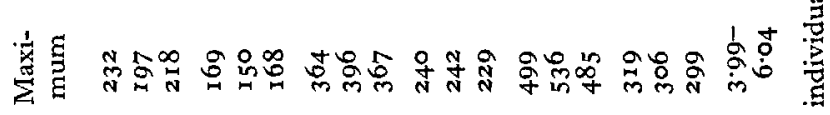

$\dot{4}$

莬 岁

题

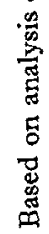

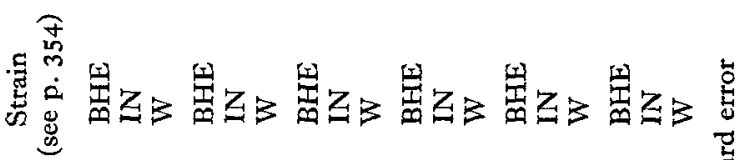

总勇要 


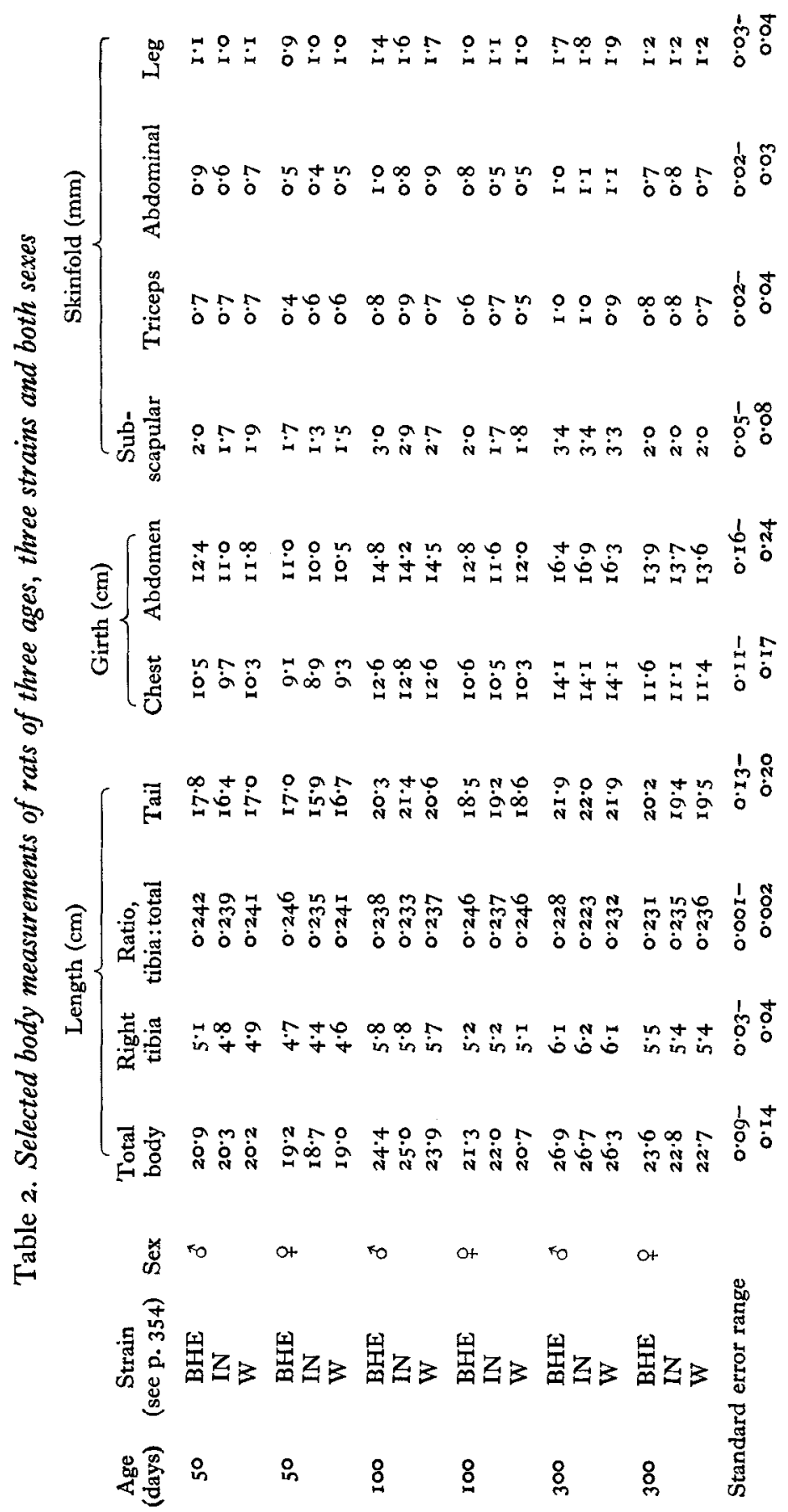


Vol. 23

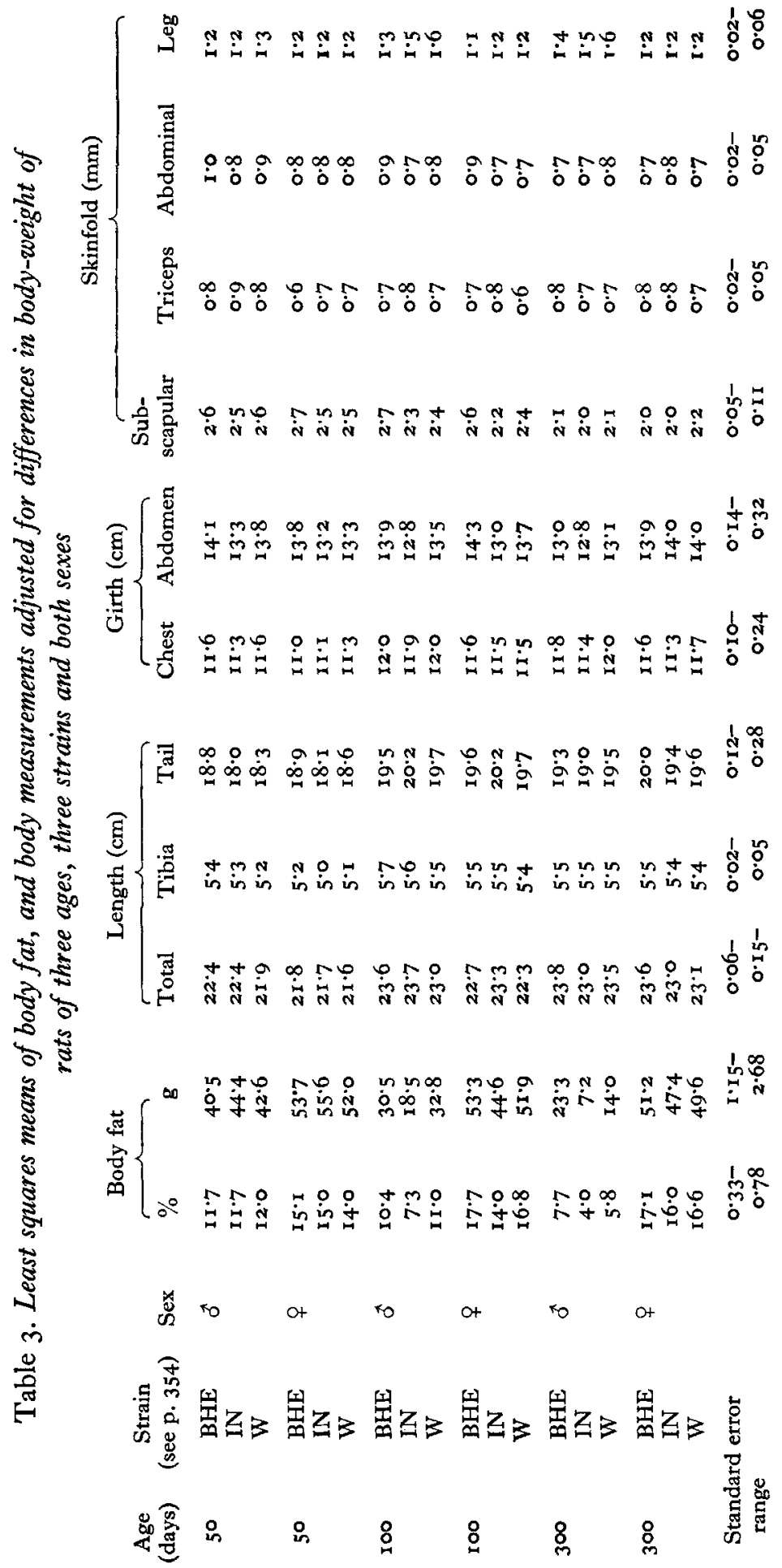


Effect of strain. Significant strain differences occurred among means for body-weight, total body fat and body measurements except for chest girth. Wistar rats were smaller and leaner than BHE rats, but the body fat of Wistar rats was not different from that of the larger IN rats. Significant differential responses for strains and sexes occurred for body-weight, body fat, tibia length and leg skinfold. This interaction was due to the similarity of females among the strains in many of the measurements, but with differences particularly in body-weight and fat occurring among the males. Among strains, body-weight did not account for significant differences for any measurement except tail length. Differences in body-weight explained the differences in body fat between BHE and Wistar rats, but the larger IN rats were still the leanest.

Effect of sex. Significant differences due to sex occurred among body-weights, body fat and all body measurements. In all instances males had the largest component parts, including total fat which was a smaller percentage of their weight than it was in females. Sex differences in tail length, abdominal girth and all skinfolds except the leg were removed when the values were adjusted for body-weight.

Age-sex interaction. Mean values for the sexes were usually closest at $5^{\circ}$ days, farther apart at 100 days and farthest at 300 days. Adjusting total fat for body-weight increased the difference between the sexes. This fact emphasizes the more rapid deposition of fat in the female. Subscapular fold and chest girth showed similar relationships for both sexes at 300 days, the period of maximum fatness. Obviously there is an increase in muscle tissue as well as in fat when chest girth and subscapular fold increase in size in the rat. The triceps skinfold showed significant age-sex interaction only when adjusted for body-weight-being smaller at 50 days for females, the same in both sexes at 100 days and larger for females at 300 days.

Age-strain interaction. IN rats were the lightest strain at 50 days and the heaviest at 100 and 300 days. Wistar rats were intermediate for weight at 50 days, approximately the same as BHE rats at 100 days and lightest at 300 days. BHE rats were heaviest at 50 days and intermediate for weight at 300 days. Mean body-weights did not parallel mean body fatness. On the average, BHE rats were fattest at all three ages but were not significantly different from Wistar at 50 and 100 days. IN rats were leanest at 50 and 100 days and not significantly different from Wistar rats at 300 days. After adjustment of the results for body-weight, IN rats were fattest for their weight at 50 days but leanest at 100 and 300 days. BHE rats had more fat for their weight than Wistar rats only at 300 days. There were no differences in tibia lengths of BHE and Wistar rats at 300 days when their body fat differed, but IN rats had the shortest tibias. IN rats had smaller chest and abdominal girths for their weight at 300 days than the other two strains, though the chest girth of BHE rats decreased at 300 days.

\section{Proximate composition}

Increases in fat-free weight and in amounts of individual components with age are shown for each sex and strain (Table $\mathbf{r}$ ). In the fat-free body, however, there was a slight decrease in the proportion of water from 50 to 100 days with no further change at 300 days. On the contrary, the proportion of protein in the fat-free body increased slightly from 50 to 100 days, though the differences were not large. The proportion. 
of ash in the fat-free body rose from 50 to Ioo days in females of all three strains, and in BHE males at this age; there was essentially no change in IN or Wistar males. Between 100 and 300 days, however, ash in the fat-free body fell in BHE rats of both sexes, in IN males and in Wistar females. Among these three strains only the Wistar males had a relatively constant proportion of ash in the fat-free body with change in weight (and age).

\section{Individual variation}

Large variations in total body fat occurred among rats of the same body-weight regardless of sex, strain or age. Variation in total fat was least at 50 days in both sexes but increased greatly at 100 and 300 days; it was considerably greater in the males than in females. When total body fat was plotted against body-weight the graph was curved, owing to the large ratio of fat to weight in some of the females at 300 days. Otherwise, on an arithmetic basis, the points would essentially fit a straight line. There was no apparent advantage in plotting the logs of these values since reduction in the variation of $100-$ and 300-day-old males and females was accompanied by a greater scatter for 50-day-old rats. Further, converting arithmetic means into logarithms and plotting body fat $(Y)$ against body-weight $(X)$ showed that the growth of fat stores was similar in all strains in relation to weight for the first two ages, except for the Wistar strain, in which the rate of growth of fat stores decreased between roo and 300 days. 'Therefore, in the Wistar strain, body fat and body-weight were not linearly related. The conclusion may be reached that either fatness or leanness may be associated with large body size, a well-documented observation in man. Drawing one line for the means of these groups would provide erroneous information as to the make-up of these individual populations.

\section{Interrelationships between body fat, body-weight and body measurements}

Table 4 shows ' $\mathrm{R}^{2}$ ' values resulting from correlation of body fat with body-weights and measurements for each of the eighteen groups of rats. These ratios show the amount of the total variation in body fat accounted for by the measurements and indicate the precision of predicting total body fat from the measurements individually. The results may be summarized as follows: (I) Correlation of variables with fat is different for groups of rats selected at different ages. In practice, most nutrition investigators do not select animals over a wide range of age and size. Results of limited studies are usually interpreted to have wide application. Such interpretations could be misleading when applied without regard for the period of time covered in studies of body composition. (2) Body measurements other than body-weight, such as length, girths and skinfold thicknesses, are good predictors of total body fat though different for different strains or sexes, and may be useful, in studies on human beings, in determining relationships between subcutaneous and total fat. (3) Although the tibia length cubed shows good correlation with total fat in groups of male or female rats, there was no difference between using the actual tibia length or tibia length cubed as a predictor. (4) Length of the rat in proportion to body-weight, though inversely related to total fat, was the only variable which yielded highly significant correlations with fat at all 


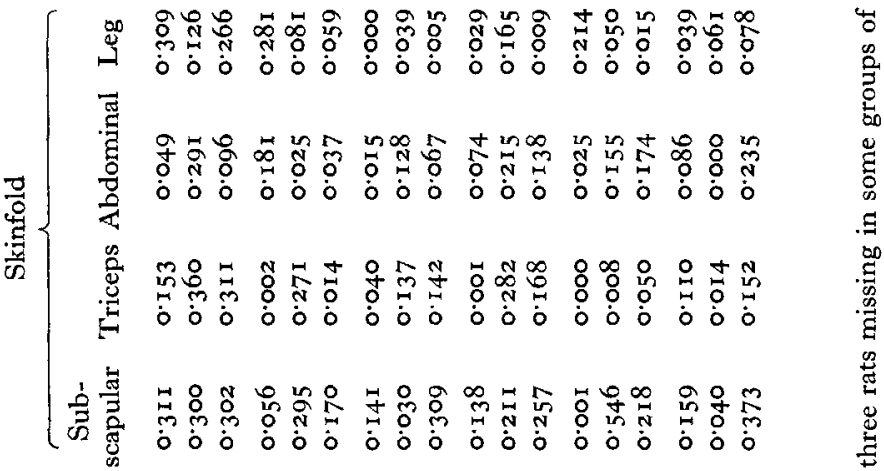

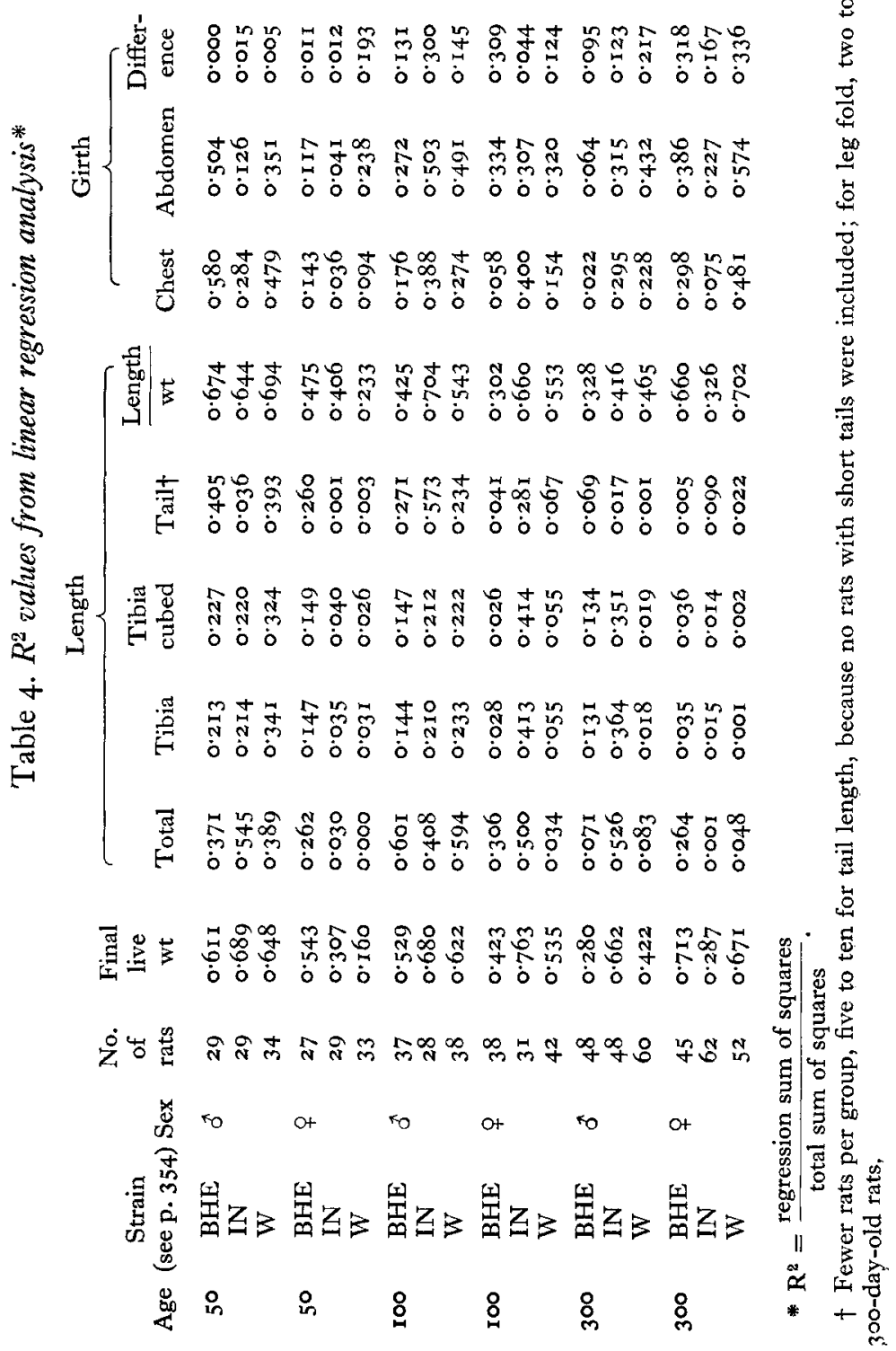


ages. (5) Differences between girths, shown to be useful as an index of body fat in man (Behnke, I963), were not as useful in the rat as were individual girths.

Tables 5 and 6 give values necessary for formulating multiple regression equations for predicting total carcass fat of both sexes of the three strains of rats at each age,

Table 5. Characteristics of multiple regression equations for predicting total carcass fat $(g)$ of both sexes of three strains (BHE, IN and Wistar) of rats at three ages

\begin{tabular}{|c|c|c|c|c|c|c|}
\hline \multirow[b]{2}{*}{$X$ variable } & \multicolumn{3}{|c|}{ Males } & \multicolumn{3}{|c|}{ Females } \\
\hline & $\mathrm{BHE}$ & IN & Wistar & $\mathrm{BHE}$ & IN & Wistar \\
\hline \multicolumn{7}{|c|}{ 50-day-old rats (I 8I) } \\
\hline & $\begin{array}{c}\bar{Y} \ddagger=11.6 \mathrm{I}^{a} \\
\pm 0.86\end{array}$ & $\begin{array}{l}12.03^{a} \\
\pm 0.55\end{array}$ & $\begin{array}{l}12.67^{a} \\
\pm 0.59\end{array}$ & $\begin{array}{l}18.04^{a} \\
\pm 0.63\end{array}$ & $\begin{array}{l}16.19^{a b} \\
\pm 0.88\end{array}$ & $\begin{array}{l}14.71^{b} \\
\pm 0.67\end{array}$ \\
\hline$X_{1} \quad$ Final wt (g) & $0.13 * * \S$ & $0.13 * *$ & $0.13 * *$ & $0.13 * *$ & $0.13 * *$ & $0.13^{* *}$ \\
\hline $\begin{array}{l}X_{2} \text { Total length } \\
(\mathrm{cm})\end{array}$ & -0.85 & -0.82 & $-2 \cdot 24 * *$ & 1.05 & $-2 \cdot 08 *$ & $-2 \cdot 35 * *$ \\
\hline $\begin{array}{l}X_{5} \text { Abdominal } \\
\text { girth }(\mathrm{cm})\end{array}$ & 0.53 & 0.53 & 0.53 & 0.53 & 0.53 & 0.53 \\
\hline $\begin{array}{l}X_{6} \quad \text { Subscapular fold } \\
(\mathrm{mm})\end{array}$ & $2 \cdot 25^{*}$ & $2 \cdot 25 *$ & $2 \cdot 25^{*}$ & $2 \cdot 25^{*}$ & $2 \cdot 25 *$ & $2 \cdot 25^{*}$ \\
\hline \multicolumn{7}{|c|}{ I00-day-old rats (214) } \\
\hline & $\begin{array}{c}\bar{Y}=21.27^{a} \\
\pm 2.88\end{array}$ & $\begin{array}{l}28 \cdot 34^{a} \\
\pm 4^{\cdot I I}\end{array}$ & $\begin{array}{l}31 \cdot 08^{a} \\
\pm 2 \cdot 3^{8}\end{array}$ & $\begin{array}{l}47 \cdot 86^{a} \\
\pm 2 \cdot 49\end{array}$ & $\begin{array}{l}33 \cdot 79^{b} \\
\pm 4 \cdot 42\end{array}$ & $\begin{array}{c}45 \cdot 43^{a b} \\
\pm 3 \cdot 51\end{array}$ \\
\hline$X_{1} \quad$ Final wt $(\mathrm{g})$ & $0.20 * *$ & $0.20^{* * *}$ & $0 \cdot 20 * *$ & $0.20 * *$ & $0.20 * *$ & $0.20 * *$ \\
\hline $\begin{array}{l}X_{2} \text { Total length } \\
(\mathrm{cm})\end{array}$ & $6 \cdot 34 * *$ & $-I \cdot 5^{8}$ & I. 50 & $0.6 \mathrm{I}$ & $I \cdot 14$ & $-I \cdot 92$ \\
\hline $\begin{array}{l}X_{4} \text { Chest girth } \\
(\mathrm{cm})\end{array}$ & $-3 \cdot 22 *$ & $-3 \cdot 22^{*}$ & $-3 \cdot 22 *$ & $-3 \cdot 22 *$ & $-3.22 *$ & $-3 \cdot 22 *$ \\
\hline $\begin{array}{l}X_{5} \text { Abdominal } \\
\text { girth }(\mathrm{cm})\end{array}$ & -0.43 & $2 \cdot 20$ & $3 \cdot 26 \dagger$ & $4 \cdot 45^{* * *}$ & -0.08 & $2 \cdot 15$ \\
\hline $\begin{array}{l}X_{6} \quad \text { Subscapular } \\
\text { fold }(\mathrm{mm})\end{array}$ & $4 \cdot 56$ & $-4 \cdot 67$ & 0.14 & 939 & $-0 \cdot 33$ & $7 \cdot 48 \dagger$ \\
\hline $\begin{array}{l}X_{7} \text { Triceps fold } \\
(\mathrm{mm})\end{array}$ & $-5 \cdot 31$ & $-12.59 \dagger$ & $-14 \cdot 94^{* *}$ & $5 \cdot 86$ & 0.83 & Io. $59 \dagger$ \\
\hline $\begin{array}{l}X_{8} \text { Abdominal } \\
\text { fold }(\mathrm{mm})\end{array}$ & $-5 \cdot 79$ & $7 \cdot 59$ & -8.87 & $-17.55^{* *}$ & $3 \cdot 84$ & $12 \cdot 45 \dagger$ \\
\hline \multicolumn{7}{|c|}{ 300-day-old rats $\left(3 \mathbf{I}_{5}\right)$} \\
\hline & $\begin{array}{c}\bar{Y}=59^{\circ} 94^{a} \\
\pm 4.40\end{array}$ & $\begin{array}{l}17.76^{b} \\
\pm 5.05\end{array}$ & $\begin{array}{l}39 \cdot 85^{c} \\
\pm 3 \cdot 44\end{array}$ & $\begin{array}{l}82 \cdot 70^{a} \\
\pm 5 \cdot 79\end{array}$ & $\begin{array}{l}55 \cdot 72^{b} \\
\pm 5 \cdot 12\end{array}$ & $\begin{array}{l}74.55^{a b} \\
\pm 5.13\end{array}$ \\
\hline$X_{1} \quad$ Final wt (g) & $0.39^{* *}$ & $0.25 * *$ & $0.35^{* *}$ & $0.56 * *$ & $0.32^{* *}$ & $0.56 * *$ \\
\hline $\begin{array}{l}X_{2} \text { Total length } \\
(\mathrm{cm})\end{array}$ & $-10 \cdot 30^{* *}$ & 0.36 & $-5 \cdot 90^{*}$ & $-3 \cdot 26$ & $-4 \cdot 26 \dagger$ & $-9 \cdot 89^{* *}$ \\
\hline $\begin{array}{l}X_{\mathrm{a}} \text { 'Tibia length } \\
(\mathrm{cm})\end{array}$ & 5.42 & $4 \cdot 16$ & - II $\cdot 00$ & $-12.39 \dagger$ & $-10.20 \dagger$ & $-\mathbf{I} \cdot 84$ \\
\hline $\begin{array}{l}X_{4} \text { Chest girth } \\
(\mathrm{cm})\end{array}$ & $-16 \cdot 82 * *$ & $2 \cdot 84$ & $-7 \cdot 66^{*}$ & $-7 \cdot 3 \mathrm{I}$ & -3.09 & -4.09 \\
\hline $\begin{array}{l}X_{5} \text { Abdominal } \\
\text { girth }(\mathrm{cm})\end{array}$ & I0.80** & $-3 \cdot 89 \dagger$ & $5 \cdot 72 * *$ & I·9I & $3 \cdot 34$ & 3.49 \\
\hline $\begin{array}{l}X_{\theta} \text { Subscapular } \\
\text { fold ( } \mathrm{mm})\end{array}$ & $-8 \cdot 20^{*}$ & $7 \cdot 2.2 *$ & -0.86 & $6 \cdot 3 \mathrm{I}$ & $2 \cdot 87$ & $2 \cdot 23$ \\
\hline
\end{tabular}

Figures in parentheses are the numbers of rats.

$\ddagger \bar{Y}=$ adjusted means and standard errors; those with the same superscript, for groups of males or females, are not significantly different. Predicted carcass fat $(\hat{Y})$ in $\mathbf{g}=$ adjusted $\bar{Y}+\left(b_{1}\right)\left(X_{1}-\bar{X}_{1}\right)$ $+\left(b_{2}\right)\left(X_{2}-\bar{X}_{2}\right)+\left(b_{3}\right)\left(X_{3}-\bar{X}_{3}\right) \ldots\left(b_{8}\right)\left(X_{8}-\bar{X}_{8}\right)$ substituting in the equation the values for the $X$ variables for an individual rat and the $\vec{X}$ values (see Table 6 ).

$\S$ Partial regression coefficients with two asterisks, $P<0.01$; one asterisk, $P<0.05$; dagger, $P<$ o.10. 
based on final live body-weight, lengths, girths and selected skinfold thicknesses. A complete regression equation includes (I) the appropriate adjusted mean, $\bar{Y}$, (2) partial regression coefficients of the $X$ variables (predictors) found to be of significance in predicting the selected $Y$ variable for each age group and for the six sex-strain

Table 6. Arithmetic means $\bar{X}$ for body measurements of rats at 50, 100 and 300 days of age used in formulating multiple regression equations*

\begin{tabular}{ll}
\multicolumn{2}{c}{ Body measurement } \\
$X_{1}$ & Final wt $(\mathrm{g})$ \\
$X_{2}$ & Total length (cm) \\
$X_{3}$ & Tibia length (cm) \\
$X_{4}$ & Chest girth (cm) \\
$X_{5}$ & Abdominal girth (cm) \\
$X_{6}$ & Subscapular fold (mm) \\
$X_{7}$ & Triceps fold (mm) \\
$X_{8}$ & Abdominal fold (mm)
\end{tabular}

50-day-old
$189 \cdot 2$
19.72
4.74
9.65
11.12
1.69
0.60
0.61

Io0-day-old
$302 \cdot 0$
$22 \cdot 77$
$5 \cdot 45$
$11 \cdot 53$
$\mathrm{I} 3 \cdot 28$
$2 \cdot 33$
0.70
0.76

300-day-old
$401 \cdot 1$
24.71
5.74
12.67
15.06
2.66
0.86
0.90

* Means for $X$ variables include all rats of each strain and sex at each age.

subclass groups (Table 5), and (3) appropriate mean values of the $X$ variables, $\bar{X}$ (Table 6). An equation to predict the total carcass fat of a 300-day-old BHE male rat would have the form

$\hat{Y}(\mathrm{~g}$ carcass fat $)=$ adjusted $\bar{Y}+\left(b_{1}\right)\left(X_{1}-\bar{X}_{1}\right)+\left(b_{2}\right)$

$$
\left(X_{2}-\bar{X}_{2}\right)+\left(b_{3}\right)\left(X_{3}-\bar{X}_{3}\right) \ldots\left(b_{8}\right)\left(X_{8}-\bar{X}_{8}\right) \text {. }
$$

substituting in the equation the values for the $X$ variables for an individual rat.

For example:

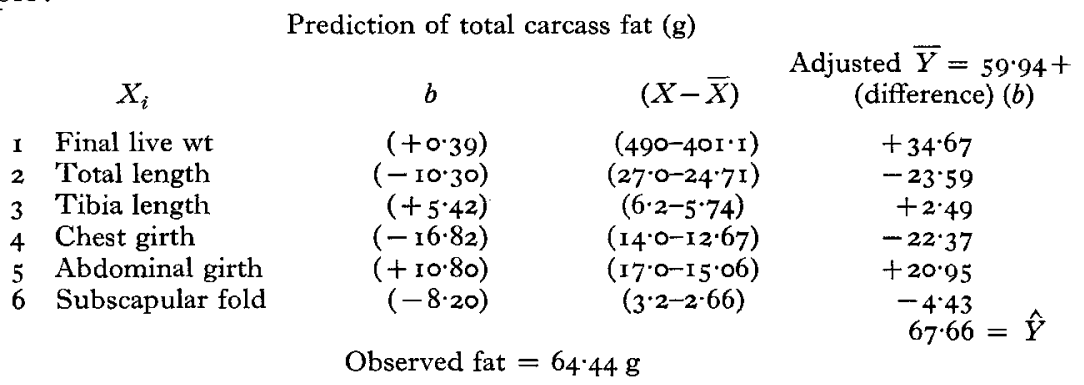

\section{Prediction of total carcass fat (g)}

As is usually the case, the equations predict best the individual values nearest the mean values of the $Y$ variables. Not unexpectedly, the predictor common to all equations was final body-weight. Body length, abdominal girth and subscapular skinfold were common to all except one set of equations. Chest girth, tibia length, triceps and abdominal skinfolds decreased in frequency of appearance in that order.

Some characteristics of the rats can be ascertained by careful perusal of the $b$ values in Table 5. For example, for the 300-day-old BHE rat, fatness is associated with shortness of the body, small chest girth, thin subscapular skinfold and large abdominal girth. On the contrary, in the leaner IN male rat of the same age fatness is associated with body dimensions in the opposite direction. In the Wistar rat of the same age, fatness is related to total length, chest girth and subscapular skinfold somewhat as in 
the BHE rat. The major difference is in the tibia length, which is shorter for the Wistar rat (not quite significant) and longer for the $\mathrm{BHE}$ rat with respect to increase in total fat.

\section{DISCUSSION}

In the present study, while we have not produced direct evidence for genetic differences in fat accumulation or metabolism among the rat strains, we have shown some indirect support for this concept. Body dimensions are known to be genetically influenced; body fat is associated with body dimensions. Therefore, body fat appears to be subject to at least indirect genetic influence. We have direct evidence that $\mathrm{BHE}$ rats are genetically variable for traits affecting fatness, i.e. the relatively lean IN strain was selectively bred from BHE animals. While body-weight is a factor, it is not the only factor. Variations in body fat of rats of the same body size may be caused by differences in food intake or utilization or in metabolic rate, with or without differences in genetic potential for fatness. The genetic factor present in BHE rats and in some individual rats of each strain apparently is not dependent upon large increases in body-weight for expression.

Although food intake of these rats fed on a commercial low-fat stock diet was not measured in the present study, previous measurements showed that the largest but leanest rats ate the most (Marshall \& Lehmann, 1967), and although BHE rats ate more of some diets than Wistar rats (Marshall \& Hildebrand, I963), differences in food intake do not explain the basic differences in the fat metabolism of these strains. Nor is there any evidence that we are aware of to indicate that food intake alone can be related to differences in fat patterning or to any relationships among dimensions of the body and location of fat depots. In fact, such relationships are thought to be hormonally influenced. Differences in gastro-intestinal contents, useful as an indication of the food habits of the three strains presented herein, were consistent with previous observations that the largest strain ate the most food. In addition, the results that show age and sex effects are clearly not the result of body size alone. It is well established that hormones influence mobilization of fat. Weber, Singhal, Stamm \& Srivastava (1965) postulated the arrangement in genetic chains of key gluconeogenic and key glycolytic enzymes which act in concert as functional units that influence the direction of a metabolic pathway. Free fatty acids operate as an effective 'metabolic directional switch' because physiological levels inhibit hepatic pyruvate kinase activity and, as a result of this inhibition, are capable of facilitating gluconeogenesis (Weber, Lea, Convery $\&$ Stamm, 1967). It is tempting therefore to speculate that in this way a balance of hormones could indeed influence an individual's potential for accumulating excess amounts of body fat.

The constancy of the fat-free body, already questioned by Wedgewood ( 1963 ), needs further investigation. But the fat-free weights of male rats in the present study showed that the chief difference in body composition of BHE and Wistar rats was fat, although differences in ash content of 300-day-old male rats were probably real. The tendency, observed in this study, for older BHE rats to become fatter than Wistar rats has been reported but is not invariably seen (Marshall \& Hildebrand, I963). With one 
stock diet (Animal Foundation Laboratory Diet; Standard Brands, Inc.) which produced kidney changes, particularly in BHE rats, small weight losses occurred and apparently obscured strain differences in body fat.

Although inter-individual variations were least among the highly inbred IN rats, we cannot explain why such large variations did occur. This finding, however, is not unusual and has been pointed out by others (Williams \& Pelton, 1966). Whether individual differences in weights, lengths and girths can be attributed only to continuous variations representative of quantitative inheritance of these traits has not yet been tested. Individual differences must be reckoned with in rate of fat storage and in requirements for individual nutrients. The importance of this recognition in man and animals has already been suggested (Williams, 1956).

The demonstration that different body dimensions are associated with different degrees and patterns of body fattening in the strains of rats studied emphasizes the need for information on inter-individual and inter-strain differences in rat populations for consideration when diet studies are conducted. Differences with a stock $v$. a purified diet have been demonstrated in total fat storage of BHE rats (Marshall, Hildebrand, Dupont \& Womack, 1959) and in in vitro lipogenesis of adipose tissue of Charles River rats (Di Giorgio, Bonanno \& Hegsted, 1962). Further investigation is needed to determine whether differences obtained in the present study with a stock diet would be the same with a purified diet.

Heredity of individual human subjects as an important source of variation in body composition was recently emphasized by Seltzer \& Mayer (1964), who dealt with the estimation of fatness with respect to genetic and constitutional factors in body build and obesity in adolescent girls. These authors consider the use of the terms overweight, relative weight, or absolute weight unsatisfactory as phenotypes in the study of obesity since they fail to take into account the body build or body composition of the individual (Seltzer \& Mayer, 1966). The use of the triceps skinfold thickness was suggested as a reliable measure of fatness in adolescent girls (Seltzer, Goldman \& Mayer, 1965). Such a decrease in chest girth with increasing age of obese human females was observed by Angel (1960). In addition, Beal (1965) demonstrated that body-weight of children, as a single concept, is inadequate without some estimate of body composition, and that calorie intake does not always have a simple positive correlation with weight.

Inheritance of body size in animals (Falconer, I960; Kidwell, Weeth, Haverland, Clark \& Shelby, 1960; MacArthur, 1944) has been established, but little is known about the inheritance of obesity except for some types of mouse (Falconer \& Isaacson, 1959; Fenton, 1956, 1960; Mayer, I963; Hanson \& Fenton, I966). Fatness in rats caused by a mutant gene was reported by Zucker \& Zucker (I96r). However, Zucker \& Zucker (1963) have not observed age-associated changes in body fat in the rat. In their strains body fat was found to be proportional to body-weight. Under conditions of forced-feeding, body-weight alone as an index of body fat in rats may be misleading (Cohn \& Joseph, 1959). However, in the present study we have found that body fat increases with age but that correction for changes in body-weight does not account entirely for differences in fatness observed at the various ages studied.

Sex differences in total fat content in rats under specific conditions also have 
been demonstrated (Reed, Yamaguchi, Anderson \& Mendel, r930; Deuel, Hallman, Movitt, Mattson \& Wu, 1944; Spray \& Widdowson, 1950; Marshall et al. 1959). In addition, a study of fat storage in six depots in rats showed differences in fat patterning between the sexes (Outhouse \& Mendel, 1933).

Relatively few studies have reported body dimensions but the need for such measurements as indices of rat growth has been stated (Acheson et al. 1959). In early studies, a definite relationship between body-weight and total length in rats was reported (Outhouse \& Mendel, 1933; Donaldson, 1924). Animals of the same age had bodies of widely different dimensions. Lengths of Yale, Long-Evans and Wistar rats (Dunn, Murphy \& Rockland, 1947) paralleled their body-weights; definite strain differences were suggested. Increase in tibia length with total length of Sprague-Dawley rats was shown to vary with age as well as with body-weight (Berg \& Harmison, 1957). Plots of $\log$ tibia length $v \cdot \log$ body length and tibia length $v \cdot \sqrt[3]{\text { weight showed that values for }}$ both sexes fell on the same line. Female Wistar rats made obese by injury to the hypothalamus were shown to have markedly different girth to length ratios from normal controls (Brooks \& Lambert, 1946). Some body measurements as well as fat of 'normal' Sprague-Dawley rats were recently reported to be significantly related to body-weight (Joy, Knauft \& Mayer, 1967 ). The effect of growth and development on the composition of animals has been studied in numerous ways. Laird (1965) suggested that the Gompertz equation more fully characterizes relative growth when large periods of time are covered. With full maturity the relationships may be characterized as a simple arithmetic process. Indeed this was so in almost all of the relationships studied herein.

One of the handicaps to progress in the prediction of body fatness has been the lack of an appropriate definition of obesity. Much progress has been made in predicting by indirect techniques the body fat content of man (Keys \& Brožek, I953; Garn \& Harper, 1955; Brožek, 1956, 1965; Young, 1964; Durnin \& Rahaman, 1967). However, more information is needed to determine why individuals vary with respect to the accuracy of the predictions.

In spite of the progress, many questions remain unanswered. How is subcutaneous fat related to total fat content? What factors are responsible for sex differences in fat content and fat patterning? Are body-weight and specific gravity the best indicators of total fatness? Is fatness inherited? If so, how? To what extent is the potential for obesity influenced by diet or metabolic defects or both?

Obviously, animals must be used to provide the kind of precise evaluation of the accuracy of indirect techniques in predicting live body composition. Specific gravity, potassium-40, body water content, creatinine excretion, cubed tibia length and bodyweight have been used with some success in predicting fat content of some animals (Rathbun \& Pace, 1945; Zucker \& Zucker, 1963; Kumar, Land \& Boyne, 1959; Martin, Kessler, Stant, Christian \& Andrews, 1963). Simple and non-traumatic techniques are desirable when the need arises, as in breeding experiments for surveying large numbers of animals for body fatness. If the rat could be used as the test animal to provide some of the answers to questions raised with respect to human body composition, an ideal situation would be presented because of the similarity of nutri- 
tional requirements for many of the metabolic processes. Perhaps characteristics of different rat strains may be representative of individual variations and the study thereof may shed some light upon this complex subject.

In the present study a series of measurements were described which can be made in less than 5 min per animal from which body fat can be predicted. It is clear that the association of these measurements with composition of the body varies with age, sex and strain of the animals studied, and that regression equations must be developed from a sample of the group to which they are to be applied. Since some types of purified diets are known to influence the rate of fat deposition in rats (Marshall et al. I959), equations may be influenced by the nature of the diet. It is clearly necessary to take into account body dimensions other than weight to obtain an optimal prediction of body fat. The complex but statistically verifiable relationships between body and skeletal measurements and carcass fat support the concept that genetic factors which influence body build also affect the accumulation of body fat.

We wish to express our appreciation to Mrs Vestine Knox, Mrs Elsie Crump and Miss Rose Harrison for assistance in care and feeding of animals; to Mrs Vestine Knox, Miss Devin Oldfield and Mr Fred Flax for technical assistance. The authors are grateful to Dr David Trout for valuable discussions during the preparation of this paper.

\section{REFERENCES}

Acheson, R. M., Macintyre, M. N. \& Oldham, E. (1959). Br. F. Nutr. 13, 283.

Adams, M. (1964). U.S. Dep. Agric. Home Econ. Res. Rep. no. 24.

Angel, J. L. (1960). Hum. Biol. 32, 342.

Beal, V. A. (1965). F. Am. diet. Ass. 46, 457.

Behnke, A. R. (1963). Ann. N.Y. Acad. Sci. I ro, 450.

Berg, B. N. \& Harmison, C. R. (1957). F. Geront. 12, 370.

Brooks, C. McC. \& Lambert, E. F. (1946). Am. F. Physiol. x47, 695.

Brožek, J. (editor) (1956). Body Measurements and Human Nutrition. Detroit, Michigan: Wayne State University Press.

Brožek, J. (editor) (1965). Human Body Composition: Applications and Approaches. Symposia for the Society for the Study of Human Biology. Vol. 7. New York: Pergamon Press,

Cohn, C. \& Joseph, D. (1959). Am. F. Physiol. 196, 965.

Deuel, H. J. Jr, Hallman, L. F., Movitt, E., Mattson, F. H. \& Wu, E. (1944). F. Nutr. $27,335$.

Di Giorgio, J., Bonnano, R. A. \& Hegsted, D. M. (1962). F. Nutr. 78, 384.

Donaldson, H. H. (1924). Mem. Wistar Inst. Anat. no. 6, and ed.

Dunn, M. S., Murphy, E. A. \& Rockland, L. B. (1947). Physiol. Rev. 27, 72.

Durand, A. M. A., Fisher, M. \& Adams, M. (1964). Archs Path. 77, 268.

Durnin, J. V. G. A. \& Rahaman, M. M. (1967). Br. F. Nutr. 21, 681.

Falconer, D. S. (1960). F. cell. comp. Physiol. Suppl. I, 56, I 53.

Falconer, D. S. \& Isaacson, J. H. (I959). F. Hered. 5o, 290.

Fenton, P. F. (1956). Am. F. Physiol. 184, 52.

Fenton, P. F. (I 960). Am. F. clin. Nutr. 8, 748 .

Garn, S. M. \& Harper, R. V. (1955). Hum. Biol. 27, 39.

Hammond, W. H. (1955). Br. F. prev. soc. Med. 9, 201.

Hanson, R. W. \& Fenton, P. F. (1966). Proc. Soc. exp. Biol. Med. 121, 343.

Harvey, W. R. (I 960). ARS 20-8, U.S. Dep. Agric.

Joy, R. J. T., Knauft, R. F. \& Mayer, J. (1967). Proc. Soc. exp. Biol. Med. 126, 869.

Keys, A. \& Brožek, J. (1953). Physiol. Rev. 33, 245.

Kidwell, J. F., Weeth, J. J., Haverland, L. H., Clark, R. T. \& Shelby, C. E. (1960). Growth 24, 47.

Kumar, I., Land, D. G. \& Boyne, A. W. (1959). Br. F. Nutr. ז3, 320.

Laird, A. K. (1965). Growth 29, 249. 
Lakshmanan, F. L. \& Adams, M. (1965). 7. Nutr. 86, 337.

MacArthur, J. W. (1944). Am. Nat. 78, 142.

Marshall, M. W. \& Hildebrand, H. E. (1 963). F. Nutr. 79, 227.

Marshall, M. W., Hildebrand, H. E., Dupont, J. L. \& Womack, M. (r959). F. Nutr. 69, 37 I.

Marshall, M. W. \& Lehmann, R. P. (I967). Metabolism I6, 763.

Martin, T. G., Kessler, W. V., Stant, E. G. Jr, Christian, J. E. \& Andrews, F. N. (1963). Ann. N.Y. Acad. Sci. 110, 213.

Mayer, J. (1963). A. Rev. Med. 14, I I.

Outhouse, J. \& Mendel, L. B. (1933). F. exp. Zool. 64, 257.

Rathbun, E. N. \& Pace, N. (1945). F. biol. Chem. 158, 667.

Reed, L. L., Yamaguchi, F., Anderson, W. E. \& Mendel, L. B. (1930). F. biol. Chem. 87, 47.

Seltzer, C. C., Goldman, R. F. \& Mayer, J. (I965). Pediatrics, Springfield 36, 212.

Seltzer, C. C. \& Mayer, J. (r964). F. Am. med. Ass. 189, 677.

Seltzer, C. C. \& Mayer, J. (1966). Ann. N.Y. Acad. Sci. 134, 688.

Spray, C. M. \& Widdowson, E. M. (r950). Br. F. Nutr. 4, 332.

Tanner, J. M. (1959). Proc. Nutr. Soc. r8, 148.

Taylor, D. D., Conway, E. S., Schuster, E. M. \& Adams, M. (1967). F. Nutr. 9r, 275.

Weber, G., Singhal, R. L., Stamm, N. B. \& Srivastava, S. K. (1965). Fedn Proc. Fedn Am. Socs exp. Biol. 24, 745.

Weber, G., Lea, M.A., Convery, H. J. H. \& Stamm, N. B. (1967). In Advances in Enzyme Regulation Vol. 5, p. 257. New York: Pergamon Press.

Wedgewood, R. J. ( (963). Ann. N.Y. Acad. Sci. rro, I41.

Williams, R. J. (1956). Biochemical Individuality. New York: John Wiley and Sons.

Williams, R. J. \& Pelton, R. B. (1966). Proc. natn. Acad. Sci. U.S.A. 55, 126.

Young, C. (1964). F. Am. diet. Ass. 45, 333.

Zucker, L. M. \& Zucker, T. F. (I96I). F. Hered. 52, 275.

Zucker, T. F. \& Zucker, L. M. (1963). F. Nutr. 80, 6. 